\title{
Sobre la comunicación a distancia: diseminaciones del archivo de arte correo del Centro de Arte Experimental Vigo
}

\section{CLARISA LÓPEZ GALARZA Universidad Nacional de La Plata, Argentina / clarisalopezgalarza@gmail.com JULIO LAMILLA Universidad Nacional de las Artes, Argentina / julio.lamilla@gmail.com}

\section{Resumen}

Este escrito surge de una revisión crítica de la primera etapa del proceso de ordenamiento y catalogación del acervo de arte correo del artista platense Edgardo Antonio Vigo. A través de las nociones de network (trabajo en red), comunicación a distancia y arte correo, indagaremos en conceptualizaciones y producciones que desplazan o subvierten las redes y los circuitos de consumo del arte del siglo XX, tensionando sus lógicas hegemónicas de circulación. A través de la recuperación de intercambios postales y estrategias de comunicación a distancia, que activaron diversas redes de solidaridad internacionales en contextos de asfixia social, censura y represión, exploraremos las potencialidades de estas estrategias para la construcción de espacios de intercambio y sostenimiento afectivos entre sus integrantes. En este sentido, nos detendremos en el arte correo como la puesta en acto de un apoyo postal recíproco, que narró situadamente y con mínima latencia el acontecer de su tiempo.

Palabras clave: network / archivos de artista / Edgardo Antonio Vigo / comunicación espórica

\section{About comunicación a distancia: dissemination of the mail art archive of the Vigo Experimental Art Centre}

Abstract

This paper arises from a critical review of the first stage of the ordering and cataloging process of the mail art collection of the platense artist Edgardo Antonio Vigo. Through the notions of network, comunicación a distancia (long distance communication) and mail art, this work investigates conceptualizations and productions that displace and subvert the networks and circuits of art consumption of the s.XX, stressing its hegemonic circulation logic. Through the recovery of postal exchanges and strategies of comunicación a distancia which activated several international solidarity networks in contexts of social asphyxiation, censorship and repression, we will explore the potential of these strategies for the construction of emotional exchange and support spaces between members. In this sense, it focuses in the mail art as the implementation of a reciprocal postal support, which narrated the situation of its time with minimal latency.

\section{Key words: network / artist archive / \\ Edgardo Antonio Vigo / sporic communication}

Recibido: 17/6/2019. Aceptado: 5/8/2019

Para citar este artículo: López Galarza, C. y Lamilla, J. (2019). Sobre la comunicación a distancia: diseminaciones del archivo de arte correo del Centro de Arte Experimental Vigo. El taco en la brea, 10 (junionoviembre), 143-149. Santa Fe, Argentina: UNL. DOI: 10.14409/tb.vii1o.8694 
Han pasado meses desde que comenzamos un trabajo colectivo de ordenamiento y catalogación de las cartas que Edgardo Antonio Vigo recibió a través del arte correo: hubo un primer intento a través de una labor individual, antes no sabemos quién ordenó las cartas por año, coriginalmente, Vigo las tenía ordenadas de algún modo? Ana María, la arconte de este archivo infinito, nos dice - medio en broma, medio en serio- que cuando terminemos de ordenar nos traerá más cartas, cartas inclusive nunca abiertas.

Hasta el momento, el fondo de Arte Correo del Centro de Arte Experimental Vigo está compuesto por más de cuatro mil envíos, de aproximadamente doscientos cincuenta artistas de los cinco continentes. Hemos identificado y ordenado, estimativamente, el setenta por ciento del material, en un proceso que estribó en elaborar un criterio topográfico que permita su ubicación en el archivo. Lejos de hacer disponible un catálogo pormenorizado de este fondo, nuestro primer objetivo se define por el establecimiento de un orden en el espacio del archivo, una primera organización que nos permita conocer y agrupar el material con el que trabajamos.

La labor consistió en agrupar artistas por regiones y países para luego armar carpetas individuales, en las que conviven materialidades diversas. En este recorrido, nos hemos hecho preguntas que permitan, por un lado, enriquecer las categorías que volverán accesible y consultable el archivo, a la vez que el arte correo nos ha propuesto una serie de interrogantes que surcan la temporalidad y la espacialidad específicas que se ponen en juego en nuestro quehacer, vinculadas a la producción y circulación de las piezas que atesoramos.

En el proceso, las preguntas-problema que han sostenido nuestro trabajo estuvieron vinculadas a las porosidades presentes en el arte correo: ¿qué es práctica artística y qué es correspondencia íntima?, ¿cómo diseccionar las fronteras entre el arte correo y la poesía visual?, ¿cómo trabajar aquellos envíos de artistas múltiples, de comunidades fugaces que se constelan en diversos espacios geográficos?

En este texto nos aproximaremos a un abordaje de estas prácticas y procesos en tanto productoras de una trama de relaciones entre productores/artistas que hace posible el establecimiento de intercambios no mediados por regulaciones institucionales, sean estas de índole política, mercantil o estética.

\section{Arte como reciprocidad. Atlas de lo incompleto}

Por ello siempre argumenté que el nombre «arte correo» está mal puesto, que debiera llamarse «arte de la comunicación» o similar (...) es un arte eterno, no puede morir (...) en tanto hayan dos interlocutores el Communicational Art es posible (...) el Eternal Network de Robert Filliou, el modelo utópico de la perpetua expansión de la comunicación a toda la humanidad, no cejará...»

Clemente Padín ${ }^{1}$

La práctica del arte correo y de comunicación a distancia ${ }^{2}$ operó desde los años 60 como un canal múltiple de traspasos de materialidades entre puntos geográficos dispersos, transformándose en puente de comunicabilidades de doble vía, red y medio técnico relacional de vinculación con el mundo, a la vez que modo de entrelazamiento de entornos y contextos geopolíticos. Esta red de artistas se constituyó en un espacio horizontal de intercambios descentralizados de información, imágenes y saberes. Al modo de una puesta en acto de una relación de producción estética no 
capitalista, ha germinado el canal de circulación del medio postal y de otras formas de comunicación a distancia. En ellos ha tensionado y subvertido el valor de cambio de los objetos estéticos, a través del desarrollo de estrategias de desmercantilización gestadas desde de la acción de este potlatch $^{3}$ en red, así como también de la conformación de comunidades instantáneas y en flujo.

Para implementar esta economía del dar infinito, la comunicación a distancia utilizó diversos gestos, uno de estos fue utilizar el espacio de habitabilidad del sobre o postal, explorar cómo estos eran potencialmente capaces de contener y activar la puesta en circulación de producciones e invitaciones al hacer. Pequeños espacios contenedores operando como museos plegados, nómades e intervenidos, desde donde derramar vastedades de obras, postales, objetos, fragmentos, sellos y estampillas de artistas, desbordes de las posibilidades de las formas de comunicación casi imposibles de aprehender para las manos de la labor archivística. Las prácticas de envío, que combinan imágenes intervenidas manualmente con aquellas producidas en serie, copias de catálogos, invitaciones y afiches, intercalan y entretejen piezas que se sitúan al interior del territorio artístico con otros documentos que las complementan y contextualizan, a la vez que construyen un espacio de intercambio y sostenimiento afectivo en una historicidad surcada por la violencia política y los exilios. ${ }^{4}$

En este sentido, privilegiaremos el uso de la noción "comunicación a distancia», que nos permitirá, siguiendo a Perneczky (Padín, 2001:3), el estudio del trabajo en red o network. Este término, lejos de abordarse a partir del establecimiento de contactos a través del servicio postal —como señalaría la expresión más acotada de «arte correo»— puede pensarse como la creación de «una cadena de comunicación homogénea en la cual todos los componentes son iguales y se eximen de las reglas de mercado y también de la tradicional dicotomía artista/público». En este sentido, el concepto de network propone dos desplazamientos. Por un lado, enfatiza su interés por la labor comunicativa y procesual; en otras palabras, por los procedimientos de ordenación, almacenamiento, reciclaje y creación de información que colaboran en la conformación de un circuito de trabajadores en red que exploran intermedialmente los recursos que la industria de la comunicación pone en sus manos. Así, el arte correo estaría contenido dentro del territorio del network, junto con otras actividades que utilicen medios de la industria de la comunicación, como por ejemplo el facsímil, el video o el audio dubbing (Padín, 2001:1). Un segundo desplazamiento se vincularía a los orígenes geográficos de estas prácticas de trabajo en red: mientras que los inicios del arte correo han sido atribuidos por la historiografía anglosajona a la acción del artista neoyorkino Ray Johnson, el network tiene sus raíces en territorios distantes de las metrópolis, atravesados por situaciones de censura política: los países de Europa del Este y algunos países de América Latina. Este alejamiento se duplicaría al interior del territorio de las artes: a partir de su estructura en red, sus autores y prácticas no se encuentran atravesados por discursos canónicos que regulen o documenten las acciones. Por su parte, el término comunicación a distancia, propuesto por E.A. Vigo (1981), vuelve posible la circulación de imágenes, informaciones y objetos, así como también la puesta en acto de un arte relacional que desborda los límites de la institución postal. En coincidencia con lo propuesto por Padín, el concepto de comunicación a distancia propone una traducción expandida y situada — desde el continente latinoamericano— de estas prácticas.

La estrategia de reciprocidad propia del eternal network — no mediada por operaciones económicas- propició la creación de reservorios de imágenes en diversos puntos del planeta, cuyo diálogo e interacción permitiría recuperar la especificidad de cada intercambio realizado. En este 
sentido, la relación entre la creación de redes y las prácticas de archivo construye un territorio complejo, que lidia con lo fragmentario y lo incompleto.

Habitualmente, estas producciones se acopiaban a partir de convocatorias abiertas, en las que no mediaba una selección realizada por un ojo experto. Aquí también nos encontramos, entonces, con un borramiento de la delimitación del territorio artístico: la comunicación a distancia apeló a circuitos de exhibición horizontales y alternativos de piezas, realizadas por productores de orígenes y trayectorias diversas. Estas materialidades múltiples anidan y disuelven la frontera entre la práctica artística y su documentación, entre el relato cotidiano y la producción de obra.

La comunicación a distancia transformada en un poli-canal de vinculación entre autores únicos, múltiples, anónimos y ficticios, adoptó como espacio de circulación vías aéreas, marítimas y terrestres. En el caso del arte correo, este tránsito quedó evidenciado en forma de huellas y certificados de paso en la superficie misma de los sobres (sellos, pliegues, estampillas, nombres, firmas, fechas y direcciones), en donde la información emerge de la alteración en la materialidad homogénea del medio, inscripciones que permitieron una primera catalogación, un primer intento de atrapar una cartografía de «captura y transposición de presencias poco visibles o comunidades espóricas» (Gutiérrez Marx, 2010:9).

El establecimiento de vínculos a distancia permitió la creación de identidades, agrupamientos o colectividades fugaces, imaginarias, ficticias y precarias, que disuelven la figura del artista y del autor, y que implican el desarrollo de estrategias de reconocimiento de elementos visuales y gráficos (sellos, estampillas, nombres de pueblos, materialidades, frases, trazos), que permitan la organización del material que compone el archivo. A modo de ejemplo, Edgardo Antonio Vigo hizo uso del seudónimo Tana Vigo para participar de las convocatorias y redes de arte correo, haciendo uso de elementos de su imaginario visual pero insinuando otra identidad que lo desmarcaba del papel de autor. A través de entrevistas realizadas en el proceso de investigación sobre los intercambios postales entre este artista y poeta platense y su colega antofagastino Eduardo Díaz Espinoza, nos hemos encontrado con relatos que refieren a Tana como la hija de Edgardo y que establecen una lectura de su producción como un universo gráfico diferenciado de su padre. La figura del autor se disuelve, también, en aquellas cartas que mediante una instrucción pedían ser reenviadas, y cuya superposición de información elimina la fuente de su primer envío.

La revisión de los materiales que componen el fondo nos aproxima, también, a los usos y flujos de recombinación permanente que E.A. Vigo daba a su archivo. Las cartas, imágenes y trozos de objetos, dialogan con otras colecciones de su archivo: los recortes de estampillas y los materiales faltantes en los envíos se encuentran en otros espacios del Centro - custodiados por colegas con los que articulamos estrategias conjuntas - a la vez que dan cuenta de cómo se activaba este acervo en sus orígenes, y qué especificidades podría tener su relación con la obra personal de este artista platense.

Para Robert Filliou, artista francés cercano a Fluxus y al Nuevo Realismo, en el espacio-tiempo de trabajo de la red de arte correo no hay vanguardia, porque nadie está atrás o adelante de nadie. Filliou en su concepto de eternal network contrapone a la lógica espacio-temporal de avanzada de la vanguardia, una lógica horizontal, antiteleológica y no competitiva basada en el dar, la creación permanente y la simultaneidad. Pareciese que este autor nos quisiera preguntar: ¿quién podría decir que alguien está delante de un otro en un sistema en red como la comunicación a distancia? (Filliou). En sus teorías y obras, representadas a través de procesos matemáticos a partir del principio de equivalencia, Filliou expone y registra un universo de múltiples hacedores creativos haciendo, 
en el cual lo no hecho, lo mal hecho, y lo bien hecho comparten el espacio temporal simultáneo y horizontal de la creación permanente. En el caso del archivo de E.A. Vigo, la comunicación a distancia operó como puente técnico de doble vía de contacto con el entorno artístico de su época: es a través del intercambio horizontal que se generan dos orillas o un millar de multiplicidades que absorben y devuelven piezas de arte y de vida. Toda técnica es técnica de vinculación con el mundo, pero la especificidad de la comunicación a distancia es comprenderse como comunidad de flujo libre de haceres. En el caso de los intercambios epistolares se trata de una práctica cuyos contenedores viajan con contenido incierto a destinatarios que reciben y envían contenido incierto a otros destinatarios, dibujando los filamentos de una trama global donde el sobre es un objeto técnico que expone, anida y guarece los mensajes o modos poéticos. La comunicación a distancia así entendida se constituye como una red aural de información libre y no algoritmizada, en donde los vínculos no están controlados mediante su datificación, un sistema de trayectos que activan una urdimbre invisible y analógica de archivos en flujo, desperdigados por el mundo, a modo de un arte espórico. ${ }^{5}$ La comunicación a distancia hace posible la intercomunicación entre comunidades autónomas de productores, situados en diversos espacios del globo; que articulan, a la manera del mundo funghi, una red en constante vinculación cuya acción se encuentra surcada por contaminaciones, préstamos, citas y re-apropiaciones de imágenes. Trama que en contraposición al flujo acelerado de la red digital actual, no basa su efectividad en su velocidad, sino como propusiera el artista correo Dámaso Ogaz en su obra «C(art)a n ${ }^{\circ} 5$ ", en una ecuación donde los elementos son acción y espera, es decir donde la demora opera como instancia de reflexión y contemplación de la propia comunicación a través del uso creativo del tiempo de espera entre cada mensaje.

\section{El arte correo como territorio: lo íntimo y lo contextual}

\footnotetext{
Ni superiores, ni coerciones, ni censuras de tipo alguno, sino únicamente el genuino gesto — quizá uno de los más desesperados— «del espontáneo intercambio de sentimientos en forma directa...» Acta del congreso descentralizado internacional de arte correo — sector Argentina— ${ }^{6}$
}

En especial en el arte correo, práctica desarrollada por múltiples artistas cuyas trayectorias profesionales y biográficas se encontraban atravesadas por regímenes dictatoriales, censuras, exilios y cercenamientos de las libertades democráticas, creó lazos de amistad y camaradería que rebasaban la circulación de convocatorias y de actividades ligadas a la práctica artística. A través de sus intercambios, configuró amistades y vínculos afectivos, delimitando un espacio íntimo de diálogo, zonas de contacto y de despliegue de aquellos sentimientos desatados por la violencia política, las privaciones de la libertad, las desapariciones y los desarraigos. Desde geografías distantes, los artecorreístas forjaron, en muchos casos, relaciones plagadas de relatos de apoyo y sostenimiento afectivo, en momentos históricos de control y persecución. En este sentido, el arte correo puede pensarse como una práctica que repone y dialoga con su contexto de emergencia, que despliega espacios de resistencia y de afecto, permitiendo comunicar sucesos y noticias, así como también ser una caja de resonancia de lecturas críticas sobre las situaciones políticas comunes:

estas volanderas cartas nuestras, lanzadas a todos los vientos son ráfagas de nuestras almas, las solidaridades de nuestros sueños, nuestra manera de vernos, los estallidos de una vitalidad comunicativa 
fundamental que queda vibrando en su entorno un fragmento de nuestra historia íntima, de la petite histoire, que nos conduce a la grande histoire que es la de nuestro continente. (E. Díaz Espinoza, comunicación personal, 11 Abril 1984)

Desde mediados de la década de 8o, el arte correo densificó sus acciones de visibilización de situaciones de violencia política en nuestro continente. Desde la producción y envío de planchas de estampillas con la leyenda Set free Palomo, que E.A. Vigo produjo en 1983, en alusión a la desaparición de su hijo Abel Luis Palomo Vigo, el arte correo exploró sus posibilidades como dispositivo de difusión y de presión internacional para la liberación de presos por razones políticas en distintos países de América Latina. En estas convocatorias, la red de artecorreístas encendió contactos que vinculaban nodos estratégicos del planeta: artistas latinoamericanos viviendo en sus tierras natales, coterráneos que habían emprendido el camino del exilio en Europa Occidental y artistas residentes del otro lado del Muro de Berlín, que mantenían viva una intercomunicación en la que se encienden procesos de producción de obras individuales y conjuntas. El estudio de las vinculaciones entre espacios geográficos distantes adquiere, entonces, otros relieves para su estudio: permite vislumbrar posicionamientos políticos y estrategias para la llamada a la acción, pero también atisba las relaciones afectivas que se construyen entre artistas que tal vez nunca se han conocido personalmente. En un mismo sobre, los afiches, convocatorias y volantes acompañan cartas manuscritas, fotografías y otras materialidades que sostienen la intimidad de los vínculos, que traman, en una misma comunicación y de una manera específica, lo político y lo afectivo.

De una manera similar, el ordenamiento del fondo de Arte Correo nos permitió acceder a otras formas de la geopolítica actual: esta práctica artística fue ampliamente explorada durante el periodo de la Guerra Fría como canal de intercambio de producciones estéticas de vanguardia al interior del Bloque del Este. Desplegando las piezas que habitan el archivo, podemos recomponer un fragmento de la historia de las prácticas artísticas en estos territorios y establecer otras circulaciones de imágenes, distanciada de los relatos más transitados de la historia de las artes contemporáneas escritas desde el Bloque Occidental —Estados Unidos y Europa occidental—. La alusión a geografías cuyos nombres y organizaciones han mutado nos da cuenta de las transformaciones de la configuración política global y abre el campo de acción para pensar en las diversas capas históricas que anidan en un territorio.

\section{Comunicaciones finales}

A través del proceso de identificación y ordenamiento de las piezas del archivo se despliega un campo de trabajo de límites imprecisos. Los envíos desbordan las categorías archivísticas habituales, a la vez que se instalan en la línea que separa y vincula la práctica artística, su documentación y la comunicación personal. Obras, que como dijimos, en su desperdigarse recorren el mundo a modo de un arte espórico. La indagación en las formas específicas de intercambio ahonda, a la vez, en las nociones de comunicación y trabajo en red que este archivo activa, sus prácticas situadas en momentos históricos específicos y plagados de préstamos y citas en sus imágenes. Se trata de formas del intercambio horizontal y espórico, líneas invisibles cuyo vínculo no está mediado por instituciones, reciprocidades subterráneas y aéreas que distorsionan el mapa de los vínculos artísticos en las últimas décadas del siglo XX. 


\section{Notas}

1 Padín, C. (2019).

2 Nos referimos a comunicación a distancia para referirnos a múltiples formas de comunicación que contienen y exceden la noción de arte correo.

3 Ritual de intercambio entre comunidades del norte de América, basado en el dar de manera excesiva.

4 Para profundizar sobre cómo el arte correo fue utilizado como medio de denuncia del encarcelamiento y desaparición de artistas durante los regímenes dictatoriales en América Latina ver López Galarza y Lamilla.
5 Gutiérrez Marx utiliza la noción de comunidades espóricas, especificando que esta, según el editor y artecorreísta mexicano César Espinosa, proviene de un primer uso dado en relación con las comunidades nacidas en los primeros años de internet por el escritor mexicano Juan José Infante.

6 Acta del Congreso descentralizado internacional de arte correo (s/f), hoja mecanografiada, archivo de Arte Correo del Centro de Arte Experimental Vigo.

\section{Referencias bibliográficas}

Aguerre, N. (2018). Edgardo Antonio Vigo y la comunicación a distancia. Bold, (5). La Plata: Papel Cosido.

Bernal, M.C. (2015). Redes intelectuales: arte y política en América Latina. Bogotá: Uniandes.

Bugnone, A. (2016). Vigo. Arte Política y Vanguardia. La Plata: Malisia.

Caraballo, J. y Padín, C. (1991). Solidaridad. Montevideo: Ed. de los autores.

Filliou, R. (1978). The Propositions and Principles of Robert Filliou (Part One). En Humanistic Perspectives in Contemporany Art, Sweden: Galerie S:t Petri/Archive of Experiment and Marginal Art.

Gutiérrez Marx, G. (2010). Arte Correo; Artistas Invisibles en la red postal. La Plata: Luna verde.

López Galarza, C. y Lamilla, J. (2019). Sobre-vivir. Fichas salitreras en el archivo de Edgardo Antonio Vigo. Redes de arte correo e intercambios trasandinos: algunas notas sobre la relación entre Eduardo Antonio Vigo y Eduardo Díaz Espinoza. En Cuadernos del Centro de Estudios de Diseño y Comunicación. Buenos Aires: Universidad de Palermo. En prensa.

Padín, C. (2001). El network y el rol del artista. Antes y después de Lyotard. Escáner cultural, (27). Santiago de Chile. http://www.escaner.cl/escaner27/acorreo.html (2019, 3 julio) en [Comentario en grupo de Facebook «Por la libre circulación del arte correo»]. https://www.facebook.com/groups/316730018505198/search/?query=es\%20un\%20arte\%20 eterno\%2C\%2ono\%2opuede\%2omorir\&epa=SEARCH_BOX 